\title{
Women Born to Older Mothers Have Reduced Fertility. Evidence From a Natural Fertility Population
}

By Niels van den Berg, Ingrid K. van Dijk and Rick J. Mourits

To cite this article: van den Berg, N., van Dijk, I. K. \& Mourits, R. J. (2021). Women Born to Older Mothers Have Reduced Fertility. Evidence From a Natural Fertility Population. Historical Life Course Studies, 10, 112-118. https://doi.org/10.51964/ hlcs9578

HISTORICAL LIFE COURSE STUDIES

Not Like Everybody Else.

Essays in Honor of Kees Mandemakers

VOLUME 10, SPECIAL ISSUE 3

2021

GUEST EDITORS

Hilde Bras

Jan Kok

Richard L. Zijdeman

E H P S

NETWORK 


\section{HISTORICAL LIFE COURSE STUDIES}

Historical Life Course Studies is the electronic journal of the European Historical Population Samples Network (EHPSNet). The journal is the primary publishing outlet for research involved in the conversion of existing European and nonEuropean large historical demographic databases into a common format, the Intermediate Data Structure, and for studies based on these databases. The journal publishes both methodological and substantive research articles.

\section{Methodological Articles}

This section includes methodological articles that describe all forms of data handling involving large historical databases, including extensive descriptions of new or existing databases, syntax, algorithms and extraction programs. Authors are encouraged to share their syntaxes, applications and other forms of software presented in their article, if pertinent, on the openjournals website.

\section{Research articles}

This section includes substantive articles reporting the results of comparative longitudinal studies that are demographic and historical in nature, and that are based on micro-data from large historical databases.

Historical Life Course Studies is a no-fee double-blind, peer-reviewed open-access journal supported by the European Science Foundation (ESF, http://www.esf.org), the Scientific Research Network of Historical Demography (FWO Flanders, http://www.historicaldemography.be) and the International Institute of Social History Amsterdam (IISH, http://socialhistory.org/). Manuscripts are reviewed by the editors, members of the editorial and scientific boards, and by external reviewers. All journal content is freely available on the internet at https://openjournals.nl/index.php/hlcs.

\section{Co-Editors-In-Chief:}

Paul Puschmann (Radboud University) \& Luciana Quaranta (Lund University)

hislives@kuleuven.be

The European Science Foundation (ESF) provides a platform for its Member Organisations to advance science and explore new directions for research at the European level. Established in 1974 as an independent non-governmental organisation, the ESF currently serves 78 Member Organisations across 30 countries. EHPS-Net is an ESF Research Networking Programme.

The European Historical Population Samples Network (EHPS-net) brings together scholars to create a common format for databases containing non-aggregated information on persons, families and households. The aim is to form an integrated and joint interface between many European and non-European databases to stimulate comparative research on the micro-level.

Visit: http://www.ehps-net.eu.
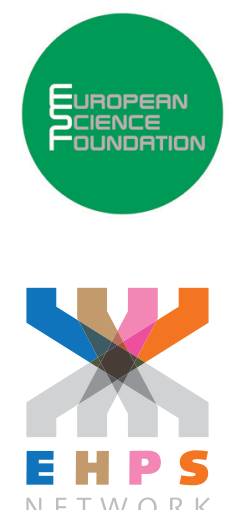


\title{
Women Born to Older Mothers Have Reduced Fertility
}

\section{Evidence From a Natural Fertility Population}

\author{
Niels van den Berg* \\ Leiden Universitair Medisch Centrum (LUMC) \\ Ingrid K. van Dijk* \\ Lund University \& Radboud University Nijmegen \\ Rick J. Mourits* \\ Utrecht University \& Radboud University Nijmegen \\ * Shared first authorship, authors in alphabetical order
}

\begin{abstract}
Are daughters of older mothers less fertile? The human mutation rate is high and increases with chronological age. As female oocytes age, they become less functional, reducing female chances at successful reproduction. Increased oocyte mutation loads at advanced age may be passed on to offspring, decreasing fertility among daughters born to older mothers. In this paper we study the effects of maternal ageing on her daughter's fertility, including total number of children, age at last birth, and neonatal mortality among her children. We study fertility histories of two generations of women from mutually exclusive families from a pre-demographic transition historical population in the Dutch province of Zeeland. Using mixed effect Poisson and linear models to take within family (sibling) relations into account, we show that among married daughters fertility is reduced for those who were born to mothers with an advanced maternal age, resulting in fewer children ever born and earlier ages at last birth. We do not find consistent evidence for effects on neonatal mortality. These results may indicate that women born to older mothers are negatively affected by their mothers' increased age.
\end{abstract}

Keywords: Fertility, Reproductive ageing, Mutation load, Maternal age, Family demography, Fertility outcomes, Neonatal mortality, Age at last birth, Reproductive senescence

e-ISSN: $\quad 2352-6343$

DOI article: $\quad$ https://doi.org/10.51964/hlcs9578

The article can be downloaded from here.

(C) 2021, van den Berg, van Dijk, Mourits

This open-access work is licensed under a Creative Commons Attribution 4.0 International License, which permits use, reproduction \& distribution in any medium for non-commercial purposes, provided the original author(s) and source are given credit. See http://creativecommons.org/licenses/. 


\section{INTRODUCTION}

Does a mother's advanced age disadvantage her daughters' reproduction? In the past decades, the age at first childbirth has increased. Understanding the consequences of late reproduction in humans is important because of the increasing postponement of childbearing. There are strong indications that children of older mothers do not fare as well as offspring of younger mothers. A wide range of animal studies show that higher parental age at conception is related to increased obesity, worse health, and fewer offspring (Hernández, van Dalen, Caswell, Neubert, \& Gribble, 2020; Schroeder, Nakagawa, Rees, Mannarelli, \& Burke, 2015). Similarly, for humans, there are also indications that women born to older mothers are less healthy, more often obese, have higher mortality and fewer offspring, and have a larger chance of staying childless than their peers (for an overview of the literature see Barclay \& Myrskylä, 2016).

Studying the extent to which these effects are related to maternal ageing in data on contemporary human populations is complicated. Children born to older mothers benefit more from secular improvements in mortality rates related to developing medical and public health conditions and educational expansion than their younger siblings (Barclay \& Myrskylä, 2016). In addition, in populations after the demographic transition, later-born children are more likely to be born to higher-educated mothers. Furthermore, the age at which children are born and the total number of children are strongly affected by the use of contraceptives and by the changed patterns of late maternal reproduction, due to assisted reproductive technology (ART). As such, for modern populations, establishing the relationship between being born to an older mother and own fertility outcomes is biased by many unobserved characteristics. Studying the consequences of late reproduction in humans requires multigenerational data from natural fertility populations, before socioeconomic differences in fertility or secular gains in lifespan, public health, and education properly set in.

We contribute to the literature on the influence of maternal age on her offspring by examining daughter's reproduction patterns using a historical demographic database. We comprehensively examine the fertility of women born to older mothers as well as their children's survival chances in a natural fertility population. Studying reproductive outcomes for older women's daughters is relevant in its own right, as it can shed light on mechanisms of reproductive ageing. Additionally, studying the trade-off between female reproduction at advanced ages and their offspring's fertility helps us understand the association between ageing and biological fitness, which are important concepts in evolutionary biology (Hernández et al., 2020).

We use a large historical database on the Dutch province of Zeeland (Mandemakers \& Laan, 2017) to study natural fertility birth cohorts, allowing us to study the total number of children instead of age at menopause, which is not necessarily affected by mutation load and oocyte quality. Life courses of women and their mothers are observed before the demographic transition, implying that there is no parity-specific birth control and that population fertility and mortality remain in an equilibrium over time. We build upon the work of Gillespie, Russell and Lummaa (2013), who showed that older mothers negatively affect offspring survival and fertility in four historical Finnish parishes. Although these first results are in line with empirical observations from animal studies, the statistical estimates may be more precise in our larger sample. Therefore, we use historical data on an entire province to assess whether and to what extent age at last childbirth, total number of children, and neonatal mortality are related to the age of the grandmother at the time of birth of the mother.

\section{DATA CONSTRUCTION AND ANALYTICAL STRATEGY}

The LINKS data contains information on individuals who were born, married or died in the Dutch province of Zeeland between 1812 and 1957. Civil certificates have been linked together into life courses and family trees, containing up to nine generations of relatives. A more extensive description of the data and the data quality may be found elsewhere (Mourits, van Dijk, \& Mandemakers, 2020; van den Berg et al., 2020). From these data, we select three-generation families (see Figure 1). The first generation, the mothers (F0), consists of women who married between 1812-1850. Mothers and their first spouse survived to the mother's 50th birthday or longer, and they had at least one child. Research persons (RPs, F1) are born between 1812 and 1874 and had their last children (F2) before 1914, with 
few births after 1900, so that results are not affected by the general decline of the number of births in the province of Zeeland during the demographic transition. In total we identified 4,428 mutually exclusive three-generation families covering 7,332 F0 parents, 9,732 F1 RPs, and 73,075 F2 children.

Figure $1 \quad$ Example family tree of the selected research persons (RPs)

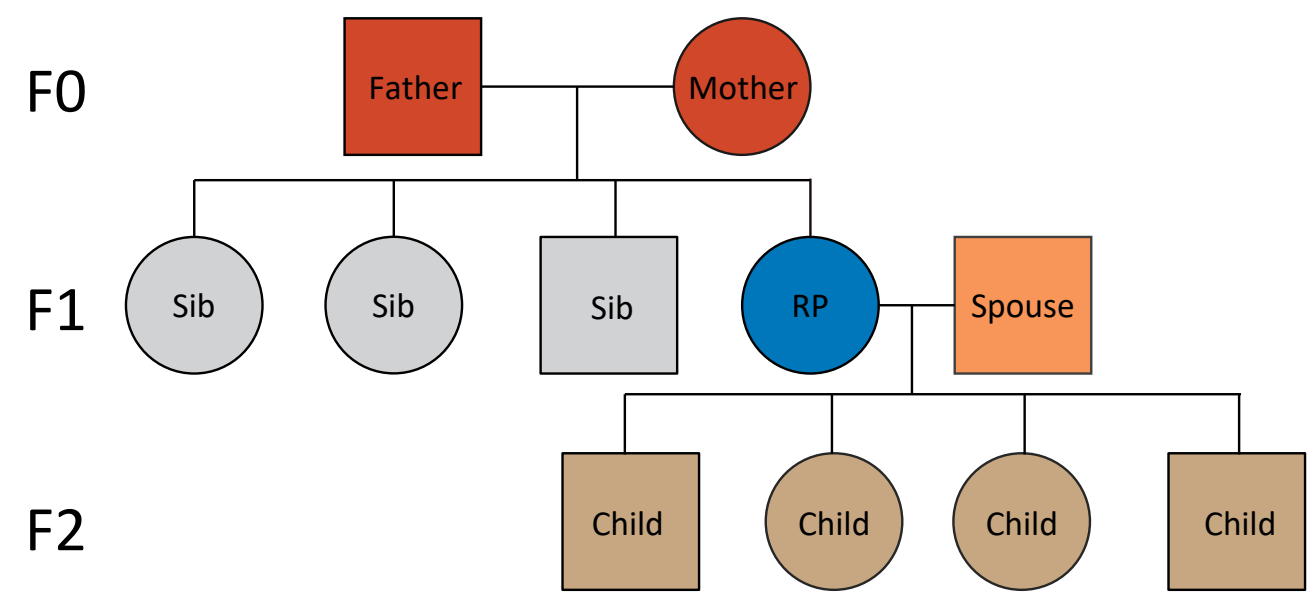

Table $1 \quad$ Descriptive statistics

\begin{tabular}{|l|l|l|l|}
\hline & F0 - Mothers & F1 - Research persons & F2 - Children \\
\hline Number (N) & 7,332 & 9,732 & 73,075 \\
\hline Deceased (\%) & $6,362(87 \%)$ & $9,732(100 \%)$ & $53,301(73 \%)$ \\
\hline Missing age (\%) & $1(<1 \%)$ & $0(0 \%)$ & $25(0 \%)$ \\
\hline Censored (\%) & $969(13 \%)$ & $0(0 \%)$ & $19,749(27 \%)$ \\
\hline Mean age at last observation & $60.03(18.23)$ & $73.9(10.43)$ & $30.15(31.30)$ \\
\hline Mean age at death & $63.41(17.07)$ & $73.9(10.43)$ & $34.33(34.48)$ \\
\hline Females (\%) & $7,332(100 \%)$ & $9,732(100 \%)$ & $35,441(48 \%)$ \\
\hline Birth cohorts & $1768-1833$ & $1812-1874$ & $1832-1914$ \\
\hline Marriage cohorts & $1812-1850$ & $1831-1905$ & $1852-1937$ \\
\hline Mean number of children & 7.66 & 7.51 & 4.89 \\
\hline
\end{tabular}

\section{RESULTS}

We estimate a Poisson distributed generalized linear mixed model to study the relation between mother's age at birth and the count distribution of 1) number of children, 2) neonatal mortality, in the first four weeks from birth, including infants who were dead upon registration (equation 1) and the Gaussian distribution of 3) age at last birth (equation 2). We model a random effect to adjust for within-family relations of the F1 RPs. Specifically, we allow a random intercept per family so that we study within-family (RPs clustered by their mothers) effects.

$$
\begin{aligned}
& \boldsymbol{Y}_{i j}=\exp \left(\beta \boldsymbol{Z}_{i j}+\gamma \boldsymbol{X}_{i j}\right)+\boldsymbol{u}_{i j} \\
& \boldsymbol{Y}_{i j}=\boldsymbol{\beta} \boldsymbol{Z}_{i j}+\boldsymbol{\gamma} \boldsymbol{X}_{i j}+\boldsymbol{u}_{i j}
\end{aligned}
$$

Where $Y_{i j}$ is a vector of responses for the $j^{\text {th }} \mathrm{F} 1 \mathrm{RP}$ of F0 mother $\mathrm{i}$ and corresponds to either the number of children and neonatal mortality (equation 1), or age at last birth (equation 2). $\beta$ is a vector of regression coefficients for the main effects of interest (Z) which corresponds to the age of the mother at the time of birth of the RP, $\gamma$ is a vector of regression coefficients for the effects of covariates and possible confounders $(\boldsymbol{X})$, which are marriage age, and birth year of the mother. $\boldsymbol{u}$ refers to an unobserved random effect shared by RPs of a given mother. In contrast to work by Gillespie, Russell and Lummaa (2013), the models are adjusted for marriage age of the RP rather than the RP's total number of children, as the RP's marriage age is a more precise estimate for the time window in which 
she could have had children. Results are controlled for possible trends over time by including the birth year of the RP's mother rather than the birth year of her children, so that trends over time and the ageing of the mother are included as two separate effects.

Table 2

Results of models of fertility careers of women (F1) by age of the mother (FO)

\begin{tabular}{|l|l|l|l|}
\hline & $\begin{array}{l}\text { Model 1 } \\
\text { Number of children }\end{array}$ & $\begin{array}{l}\text { Model 2 } \\
\text { Neonatal mortality }\end{array}$ & $\begin{array}{l}\text { Model 3 } \\
\text { Age last birth }\end{array}$ \\
\hline Age mother at birth RP & & & \\
IRR $(95 \% \mathrm{Cl})$ & $0.997(0.996 / 0.999)$ & $0.995(0.990 / 1.000)$ & $-0.025(-0.010 /-0.040)$ \\
p-Value & $2.38^{*} 10^{-3}$ & $5.41^{*} 10^{-2}$ & $1.01^{*} 10^{-3}$ \\
\hline Marriage age RP & & & \\
IRR (95\% CI) & $0.941(0.939 / 0.943)$ & $0.980(0.973 / 0.987)$ & $0.177(0.156 / 0.199)$ \\
p-Value & $<2.00^{*} 10^{-16}$ & $4.11^{*} 10^{-8}$ & $<2.00^{*} 10^{-16}$ \\
\hline $\begin{array}{l}\text { Birth year mother } \\
\text { IRR (95\% Cl) }\end{array}$ & $0.997(0.997 / 0.998)$ & $0.993(0.990 / 0.996)$ & $-0.030(-0.021 /-0.038)$ \\
p-Value & $1.21 * 10^{-7}$ & $4.16^{*} 10^{-6}$ & $1.46^{*} 10^{-11}$ \\
\hline $\mathrm{N}$ & 9,732 & 9,732 & 9,732 \\
\hline
\end{tabular}

Note: Every column represents a separate model with control variables. For example, model 1 assesses the effect of the age of the RP's mother at the RP's birth on the RP's number of children while controlling for the marriage age of the RP and the birth year of the RP's mother. Number of children is the number of F2 children born to F1 RPs. Neonatal mortality corresponds to mortality among F2 children during the first four weeks from birth, including infants who were dead upon registration. Age at last birth refers to the F1 RP's age at last birth. Birth year mother refers to the year of birth of the FO mother.

The results provide evidence that daughters of older mothers have a decreased fertility. In Table 2, we show that the incidence rate ratio (IRR) for number of children is 0.997 . This indicates that for every unit increase in the age of RP's mother at birth of the RP the incidence rate of number of children decreases by a factor of 0.997 or, in other words, decreases with $0.3 \%$. The effect is thus robust but small. Furthermore, we find that the age at last birth is lower for women with older mothers $(-0.025$, $95 \% \mathrm{Cl}:-0.010 /-0.040)$. For each yearly increase in the age at birth of the mother, her daughter's age at last birth decreased with 9 days. Finally, the neonatal mortality is lower among women with older mothers, but the effect is not very precisely estimated and marginally insignificant $(0.995$, $95 \% \mathrm{Cl}: 0.990 / 1.000$ ). Additional analyses (tables can be provided upon request) show that the effect on neonatal mortality is limited to the earlier cohorts and disappeared when child mortality started declining and less than $30 \%$ of the newborns died in first year of life. Neonatal mortality consequences of motherhood at advanced ages are likely to be even lower in modern low-mortality contexts, but there is little reason to assume that fertility consequences among women with older mothers have dissipated over time.

\section{DISCUSSION AND CONCLUSIONS}

We presented evidence that late maternal reproduction is associated with multiple negative health outcomes in her daughters in a natural fertility population in Zeeland, The Netherlands, 1812-1874. As the age of their mother increased, women's own number of children decreased and their age at last birth declined. These outcomes are in line with earlier studies which showed that late reproduction is associated with decreased reproduction in various animals and an earlier age at menopause in humans. It has been hypothesized that one of the main drivers behind this effect is aging of the germ cells (reproductive ageing) (Cawthon et al., 2020). Over the life time mutations, both in somatic and germ cells, accumulate, albeit at a much slower rate in germ cells. These mutations are associated to a decreased fertility and health (Holmes, Bernstein, \& Bernstein, 1992). Older mothers higher germ cell mutation rate is possibly related to a higher germline mutation rate in their children (Cawthon et al., 
2020; Schroeder et al., 2015). Higher germline mutation rates related to a reduced reproduction for later-born children are consistent with our findings.

Earlier research may also provide an alternative explanation for our findings. With age, the length of telomeres decreases. Telomeres are the protective ends of chromosomes and shorten with every cell division until the telomere is critically shortened and the cell dies. Telomere length is therefore strongly associated with chronological age, including age-related diseases, and there is some evidence from animal studies that telomere length is heritable. As a consequence, daughters of older mothers may have shorter telomeres, which may be related to accelerated and reproductive ageing, possibly resulting in reduced fertility (Schroeder et al., 2015).

The association between maternal age at birth and offspring fertility may not only be caused by effects of reproductive ageing, but also by the cumulative effects of longer reproduction and the composition of the sibship, including their age differences and number. In Zeeland, older mothers not only reproduced until advanced ages, but also gave birth to more children during their lifetime. Due to nutritional deficiencies and short birth intervals, women had little time and (nutritional) resources to physically recover from previous pregnancies, a phenomenon known as maternal depletion. The physical depletion of mothers is related to decreased birth weight among their children and a range of negative health outcomes that relate to nutritional status, which made their children more vulnerable in the first years of life. Long-run negative outcomes may include children's observed fertility outcomes. The larger number of children may contribute to sibling competition and transmission of childhood disease between closely spaced siblings. In this study, we controlled for the negative effects of maternal depletion and larger sibship sizes by including the time windows in which married women could receive children. However, in future work, effects of maternal depletion should be further disentangled from the effects of reproduction at higher ages on children's health, for example by focusing specifically on mothers who start their reproductive career relatively late.

On the other hand, late reproduction could also signify relatively good health for some women, especially for women who had already had a larger number of children. A study on a historical population from Utah showed that mortality rates are decreased for children born to mothers with the capacity to reproduce at advanced ages, conditional on her survival to age 50 (Hin, Ogórek, \& Hedefalk, 2016). As such, mothers who are able to have children at an advanced age may be relatively robust and their survival advantage, on average, may be shared with their children. At the same time, their relative robustness may not be shared with all their children equally. As we have illustrated in the current work, late-born children may be subject to patterns of accelerated (reproductive) ageing and decreased fertility. Children born to older mothers may therefore, benefit from their mother's relative robustness, but at the same time late-born children may be subject to patterns of accelerated (reproductive) ageing and decreased fertility due to their mother's advanced age at birth. How children of older mother's ageing and survival at later ages are affected by these two counteracting effects remains an open question.

Second, women who have older mothers have, on average, different family networks than their earlierborn siblings. They are more likely to lose their parents at a young age, especially in historical populations with shorter adult life expectancy, which increases their mortality and may hasten their transition into marriage (Störmer \& Lummaa, 2014). When daughters marry and have children themselves, later-born children in the sibship have older parents who are less likely to be alive and help raise their grandchildren. A body of earlier research has suggested that especially maternal grandmothers contribute positively to their daughter's reproduction and infant and child survival (Hawkes, 2013; Sear \& Mace, 2008). As such, women with older mothers may be relatively disadvantaged when their children are young and neonatal mortality among their children could be relatively higher, due to differences in their family networks.

In sum, mother age at birth has a small, but wide-ranging effect on her offspring's life course. Daughters of older mothers had fewer children of their own, and had their last child at an earlier age. These insights from 19th century Zeeland are still very much relevant today. Reproduction is more limited today and subject to deliberate birth control, but since the 1970s the average age at last birth has increased and late-age reproduction has become more common than in the mid-century. Although late reproduction is not a historical exception, as women had children throughout their fertile window in recent history, we have shown evidence that having children at advanced ages may come at a 
price. Research in contemporary data is necessary to investigate to what extent maternal age affects offspring fertility today.

In future work, further disentanglement of the impact of maternal age on children's reproduction should take fathers into account next to mothers. Next to women, men's reproductive career could be affected by parental mutation accumulation indicated by mother's advanced age at their birth (Arslan et al., 2017; Hayward, Lummaa, \& Bazykin, 2015). Furthermore, marital success may play a key role in linking together mother's age and her children's own fertility, both from a social and a biological perspective. Children of older mothers, and to some extent also fathers are more prone to have health syndromes, such as Down's syndrome, and other physical deficiencies, which could lead to lower marital and reproductive success. Children of older parents may be disadvantaged on the marriage market also due to caretaking burdens for their parents (Hayward et al., 2015). Evidence presented here concerns married individuals, and more wide-ranging effects of advanced maternal age on reproduction may be identified taking into account a broader selection of her children, but is beyond the scope of this paper. To conclude, the ramifications of late reproduction on offspring health are much broader than the presented evidence that reproduction and reproductive ageing are affected by maternal age at birth and socio-biological frameworks are necessary to understand why.

\section{ACKNOWLEDGEMENTS}

We are greatly indebted to Kees Mandemakers for his indispensable labor on the HSN and LINKS projects throughout the last 30 years. These projects made it possible to study life courses, familial ties, intergenerational effects, and demographic patterns for the 19th and 20th century Netherlands. Initially, for a sample of the Dutch historical population, then as the entire historical population of the province of Zeeland, and in the near future of the entire country of the Netherlands. These projects have radically improved historiography related to the social, economic and demographic developments in the history of The Netherlands. Work such as presented here would not be possible without Kees' efforts to advance our knowledge of the Dutch population history. We thank Kees for his efforts throughout his career to advance these projects.

Ingrid van Dijk has been funded through the research programme 'Landskrona Population Study', funded by the Swedish Foundation for Humanities and Social Sciences (Riksbankens Jubileumsfond).

\section{REFERENCES}

Arslan, R. C., Willführ, K. P., Frans, E. M., Verweij, K. J. H., Bürkner, P-C., Myrskylä, M., Voland, E., Almqvist, C., Zietsch, B. P., \& Penke, L. (2017). Older fathers' children have lower evolutionary fitness across four centuries and in four populations. Proceedings of the Natural Society B: Biological Sciences, 284(1862), 20171562. doi: 10.1098/rspb.2017.1562

Barclay, K., \& Myrskylä, M. (2016). Advanced maternal age and offspring outcomes: Reproductive aging and counterbalancing period trends. Population and Development Review, 42(1), 69-94. Retrieved from www.jstor.org/stable/44015615

Cawthon, R. M., Meeks, H. D., Sasani, T. A., Smith, K. R., Kerber, R. A., O'Brien, E., Baird, L., Dixon, M. M., Peiffer, A. P., Leppert, M. F., Quinlan, A. R., \& Jorde, L. B. (2020). Germline mutation rates in young adults predict longevity and reproductive lifespan. Scientific Reports, 10, 10001. doi: 10.1038/s41598-020-66867-0

Gillespie, D. O. S., Russell, A. F., \& Lummaa, V. (2013). The effect of maternal age and reproductive history on offspring survival and lifetime reproduction in preindustrial humans. Evolution, 67(7), 1964-1974. doi: 10.1111/evo.12078

Hawkes, K., \& Coxworth, J. E. (2013). Grandmothers and the evolution of human longevity: A review of findings and future directions. Evolutionary Anthropology: Issues, News, and Reviews, 22(6), 294-302. doi: 10.1002/evan.21382 
Hayward, A. D., Lummaa, V., \& Bazykin, G. A. (2015). Fitness consequences of advanced ancestral age over three generations in humans. PLOS ONE, 10(6), e0128197. doi: 10.1371/journal. pone.0128197

Hernández, C. M., van Daalen, S. F., Caswell, H., Neubert, M. G., \& Gribble, K. E. (2020). A demographic and evolutionary analysis of maternal effect senescence. Proceedings of the National Academy of Sciences, 117(28), 16431-16437. doi: 10.1073/pnas.1919988117

Hin, S., Ogórek, B., \& Hedefalk, F. (2016). An old mom keeps you young: Mother's age at last birth and offspring longevity in nineteenth-century Utah. Biodemography and Social Biology, 62(2), 164-181. doi: 10.1080/19485565.2015.1124325

Holmes, G. E., Bernstein, C., \& Bernstein, H. (1992). Oxidative and other DNA damages as the basis of aging: A review. Mutation Research/DNAging, 275(3-6), 305-315. doi: 10.1016/09218734(92)90034-M

Mandemakers, K., \& Laan, F. (2017). LINKS dataset Genes Germs and Resources, WieWasWie Zeeland, Civil Certificates, version 2017.01 [Data file and code book]. Amsterdam: IISH.

Mourits, R. J., van Dijk, I. K., \& Mandemakers, K. (2020). From matched certificates to related persons: Building a dataset from LINKS-Zeeland, Historical Life Course Studies, 9, 49-68. Retrieved from: https://hdl.handle.net/10622/23526343-2020-0006

Schroeder, J., Nakagawa, S., Rees, M., Mannarelli, M.-E., \& Burke, T. (2015). Reduced fitness in progeny from old parents in a natural population. Proceedings of the National Academy of Sciences, 112(13), 4021-4025. doi: 10.1073/pnas.1422715112

Sear, R., \& Mace, R. (2008). Who keeps children alive? A review of the effects of kin on child survival. Evolution and Human Behavior, 29(1), 1-18. doi: 10.1016/j.evolhumbehav.2007.10.001

Störmer, C., \& Lummaa, V. (2014). Increased mortality exposure within the family rather than individual mortality experiences triggers faster life-history strategies in historic human populations. PloS One, 9(1), 1-9. doi: 10.1371/journal.pone.0083633

van den Berg, N., van Dijk, I. K., Mourits, R. J., Slagboom, P. E., Janssens, A. A. P. O., \& Mandemakers, K. (2020). Families in comparison: An individual-level comparison of life-course and family reconstructions between population and vital event registers. Population Studies, 25(3),484526. doi: 10.1080/00324728.2020.1718186 